\title{
Modelling and Forecasting the Volatility of the Daily Returns
}

\section{of Nigerian Insurance Stocks}

\author{
Dallah Hamadu (Corresponding Author) \\ Department of Actuarial Science and Insurance \\ University of Lagos, Akoka-Yaba, Lagos, Nigeria
}

Tel: 234-80-3909-4884 E-mail: Dallaram2007@yahoo.com,dhamadou@unilag.edu.ng

Ade Ibiwoye

Department of Actuarial Science and Insurance

University of Lagos, Okoka-Yaba, Lagos, Nigeria

E-mail: adeibiwoye@yahoo.com

\begin{abstract}
This paper examines the volatility of the daily returns of Nigerian insurance stocks. Using empirical analysis, the study shows that the Exponential Generalized Autoregressive Conditional Heteroskedastic (EGARCH) model is more suitable in modelling stock price returns as it outperforms the other models in model-estimation evaluation and out-of-sample volatility forecasting. Given the cardinal role of insurance in Nigeria's risk management system the present findings can be useful in understanding insurance industry's stock risk. The policy implications are also considered.
\end{abstract}

Keywords: Insurance Stocks Returns, Volatility modelling, GARCH, TARCH, EGARCH, Out-of Sample Forecasts

\section{Introduction}

Volatility modelling and forecasting have attracted much attention in recent years in emerging stock markets. For instance, many asset-pricing models used volatility estimates as a simple actuarial risk measure. In Nigeria volatility modelling and forecasting has not attracted the deserved attention possibly because the stock market is largely under-developed. This phenomenon is more pronounced in the insurance sector where many of the players appear to deliberately avoid listing on the stock exchange because no information would then need to be disclosed to their shareholders. However, changes are being observed as the last two decades have seen accelerated growth of insurance markets. Arena (2006) reports that "emerging markets have recently experienced significantly faster real growth of their insurance sectors than industrialized countries reflecting liberalization and financial integration, usually following the implementation of structural reforms".

Recapitalization of the insurance industry in Nigeria has no doubt recorded a huge volume of business, the sector was able to pull an aggregate gross premium income of N90 billion in 2006, over $18 \%$ more than 2005 . Moreover, Nigerian investors' attitude and perception of insurance stocks are dramatically changing positively. In fact, discerning investors have since identified insurance stocks as a very important investment line since most of the insurance stocks are having impressive returns (Ibiwoye and Adeleke, 2008). Hence, there is currently a high level of investors' interest for insurance stocks in the market and subsequently a high level of volatility. Therefore, hedging against risk and for portfolio management, reliable risk volatility estimates and forecasts of these stocks are quite useful and need to be investigated. In Nigeria, volatility modelling and forecasting have not attracted much attention for the simple reason that the stock market is largely undeveloped. The few exceptions have been the study by Ologunde et al (2006) which fitted a regression model to the relationship between market capitalization and interest rate, Ibiwoye \& Adeleke (2008) who analysed price movements in insurance stocks pre-and post- 2005 consolidation and that of Olowe (2009) on the impact of the 2005 re-capitalization of the insurance industry on the stock market. This paper fills the gap in the emerging economy literature by investigating the volatility of Nigerian insurance stocks returns using heteroskedastic conditional volatility models.

\section{Literature Review}

The pervasive daily return volatility in equity stock markets has attracted considerable attention in the literature in recent times (Galeotti and Schiantarelli, 1994; Mankiw et al 1991; Kumar and Makhija, 1986, Schwert, 1989; Eraker, 2004). Mathematical models are usually employed to predict the future behavior of stock prices because most transactions in stocks, whether to buy or sell, are activities that take place in the future (Chauvin, 2006). In the 
past, much modelling attention had been focused on the predictable component of the stock return series. Later attention shifted to the error term whereby it is assumed that the latter is normally distributed.

Schwart (1989) found that the amplitude of the fluctuations in aggregate stock volatility is difficult to explain using simple models of stock valuation and that there is a strong residual autocorrelation using least squares hence he applied ARMA (1, 3) model for the errors. Eraker (2004) developed an approach based on Markov Chain Monte Carlo (MCMC) simulation, which allows the investigation to estimate the posterior distributions of the parameters as well as the unobserved volatility and jump processes. Rydberg (2000) reviewed some models that have been used to describe the most important or stylized features of financial data. These include fact tools, asymmetry-symmetry, volatility clustering, aggregation Gaussianicity, quasi-long-range dependence and seasonality. Rydberg (2000) classified the models into two broad categories: mathematical finance models and econometric models. Since the goal of the latter is usually forecasting it requires less rigorous probability theory than the previous and tends to focus more on the correlation structure of the data.

Models that assume normally distributed log returns like the Black \& Scholes model had been extensively used in the mathematical finance literature but this assumption has been disputed (Rydberg, 2000). More recently, attention has shifted towards modelling financial-market asset returns by processes other than normal error distribution. It has been established that the variances of the error terms in ordinary least square (OLS) estimates are not equal, and are indeed larger for some points or ranges of data than for others (Engle, 2001). This incidence of heteroskedasticity in which the usual procedures for estimating standard errors and confidence intervals fall short are best addressed by ARCH/GARCH models (Engle, 2001). The ground breaking work of Engle (1982) introduced a means of capturing the property of time-varying volatility. Further research, however, has shown that in practical applications of the ARCH (q) model, large q's are usually required thereby necessitating the need for many parameters (Rydberg, 2000). To overcome this difficulty, Bollerslev (1986) and Taylor (1986) modified the basic ARCH model as Generalized Autoregressive Conditional Heteroskedasticity (GARCH) model.

GARCH has since gained widespread acceptance in the literature and is often used for modelling stochastic risk volatility in financial time series. Floros (2007) used various GARCH models with bootstrapped out-of-sample period data to evaluate the performance of minimum capital risk requirement (MCRR) estimates. The models show that higher capital requirements are necessary for a short position, since a loss is then more likely.

David (1997) classified the models for describing the properties of stock market returns into two - the fast learning model and the slow learning model. Exploring the properties of exponential GARCH model for measuring the asymmetry between returns and volatility, David (1997) found that the fast learning model generates a negative relationship while the slow model generate returns that exhibit greater excess kurtosis. Other ARCH/GARCH based studies include Amin and Ng (1997); Baillie and DeGennaro (1990); Chahal and Wang (1998) and Chan et al (1991). Amin and Ng (1997) argue that implied volatility dominates the GARCH terms and therefore include an entire lag structure through GARCH persistence terms in their study.

However, as Rydberg (2000) had observed, neither the ARCH nor the GARCH models consider both asymmetry and leverage (the fact that volatility negatively correlated with changes in stock returns). Although GARCH (p, q) models give adequate fits for most equity-return dynamics, these models often fail to perform well in modelling the volatility of stock returns because GARCH models assume that there is a symmetric response between volatility and returns. GARCH models are thus unable to capture the "leverage effect" of stock returns. For equities, it is often observed that downward movements in the market are followed by higher volatilities than upward movements of the same magnitude. To account for this, Zakoian (1990) and Glostan, Jagannathan, and Runkle (1993) introduced the threshold GARCH (TGARCH) to take care of existing leverage effect. During the same period Nelson (1991) proposed the Exponential GARCH (EGARCH) models in order to model asymmetric variance effects.

\section{Material and Methods}

\subsection{Data for the Study}

The data for this study are from daily closing prices of insurance companies stocks traded on the floor of the Nigerian Stock Exchange (NSE). The time series data cover almost eight years starting from $15^{\text {th }}$ of December 2000 to $9^{\text {th }}$ of September 2008 and coincidently the period corresponds to Nigeria's recent stable market economy and civil democratic governance. Although about twenty-six insurance companies are listed on the floor of NSE, some of them did not survive the consolidation exercise. We are considering only the data of nine major insurance companies which daily listed stock prices are available for the period considered in the study. We used the daily data from $15^{\text {th }}$ of December 2000 to June $9^{\text {th }} 2008$ as training data set, and the data from 10 June 2008 to $9^{\text {th }}$ September 2008 as evaluation test set or out-of-sample datasets (partial data sets excluding holidays). Details on 
these companies can be found in Nigerian Insurance Digest (2007) and the data are available on http://www.cascraft.com.

\subsection{Methods}

3.2.1 Models Specification

Having observed $P_{t}$ which is denoting the stock price at time $t$, let $r_{t}=\ln \left(\frac{P_{t}}{P_{t-1}}\right)$ be the continuously compounded return series of interest. Usually, the return series is decomposed into two parts, the predictable and the unpredictable as:

$$
r_{t}=E\left(r_{t \mid t-1}\right)+\varepsilon_{t}
$$

where $E\left(r_{t \mid t-1}\right)$ is the conditional mean of return at time $t$ depending upon the information available at time $t$ - 1 and $\varepsilon_{t}$ is the prediction error term. Unfortunately, the conditional mean does have the ability to give useful predictions, hence, the recourse to methods (addressing the volatility of the error tern) such as ARCH and stochastic volatility models in modern applied statistics and mathematical finance. Assuming the unpredictable component in (1) is an ARCH process, it be written as

$$
\varepsilon_{t}=z_{t} \sigma_{t}
$$

where $z_{t}{ }^{i i d} \sim N(0,1)$ and $\sigma_{t}^{2}$ is the conditional variance.

$\operatorname{ARCH}(\mathbf{p})$

Since the seminal paper of Engle (1982) a rich literature has emerged for the modelling of heteroskedasticity in financial time series. Engle (1982) introduced the ARCH (p) model in which the conditional variance $\sigma_{t}^{2}$ is a linear function of lagged squared residuals $\varepsilon_{t}$

$$
\sigma_{t}^{2}=\alpha+\beta_{1} \varepsilon_{t-1}^{2}+\beta_{2} \varepsilon_{t-2}^{2}+\ldots+\beta_{p} \varepsilon_{t-p}^{2}
$$

Where, $\alpha>0$ and $\beta_{i} \geq 0$ and $\varepsilon_{t} \mid \phi_{t-1} \sim N\left(0, \sigma_{t}^{2}\right)$

and $\phi_{t}$ is the information set of all information up to time t. It is important to note that for ARCH models the unconditional distribution of $\varepsilon_{t}$ is always leptokurtic. In applications of the ARCH (p) model, it often turned out that the required lag $\mathbf{p}$ was rather large. In order to achieve a more parsimonious parameterization, then, Bollerslev (1986) introduced the generalized ARCH (p, q) model (GARCH (p,q)).

\section{$\operatorname{GARCH}(\mathbf{p}, \mathbf{q})$}

thus, the volatility model is now written as

$$
\sigma_{t}^{2}=\alpha_{0}+\alpha_{1} \varepsilon_{t-1}^{2}+\ldots+\alpha_{p} \varepsilon_{t-p}^{2}+\beta_{1} \sigma_{t-1}^{2}+\ldots+\beta_{q} \sigma_{t-q}^{2}
$$

where, $\alpha_{i}>0$ and $\beta_{j}>0$ for all $i$ and $j$.

In general, the value of $p$ in (4) will be much smaller than the value of $p$ in equation (3).

Important limitations of $\mathrm{ARCH}$ and GARCH models are the non-negativity constraints of the' $\alpha_{i}$ 's and $\beta_{j}$ 's which ensure positive conditional variances. Moreover, GARCH models assume that the impact of news on the conditional volatility depends only on the magnitude, but not on the sign, of the innovation. As mentioned above, empirical studies have shown that changes in stock prices are negatively correlated with changes in volatility. To overcome this

\section{$\operatorname{TARCH}(\mathbf{p}, \mathbf{q})$ Model}

The threshold GARCH, or TARCH (p, q), (Glosten et al. 1993,) is

$$
\sigma_{t}^{2}=\alpha_{0}+\sum_{i=1}^{q}\left(\alpha_{i} \varepsilon_{t-1}^{2}\right)+\gamma \varepsilon_{t-1}^{2} d_{t-1}+\sum_{j=1}^{p}\left(\beta_{j} \sigma_{t-j}^{2}\right.
$$

where $d_{t}=1$ if $\varepsilon_{t}<0$, and $d_{t}=0$ otherwise. In this, good news $\left(\varepsilon_{t}<0\right)$, and bad news $\left(\varepsilon_{t}>0\right)$, have differential effects on the conditional variance. In this work we consider popular TARCH $(1,1)$. In this case, good news has an impact of $\alpha$ and bad news has an impact of $\alpha+\gamma$.

EGARCH (p, q) Model

Similarly, to o overcome the drawbacks, Nelson (1991) introduced the exponential GARCH. As: 


$$
\ln \left(\sigma_{t}^{2}\right)=\alpha_{0}+\sum_{i=1}^{q}\left(\alpha_{i}\left|\frac{\varepsilon_{t-i}}{\sigma_{t-i}}\right|+\gamma_{i}\left(\frac{\varepsilon_{t-i}}{\sigma_{t-i}}\right)\right)+\sum_{j=1}^{p}\left(\beta_{j} \ln \left(\sigma_{t-j}^{2}\right),\right.
$$

The EGARCH $(1,1)$ used in the present study is the EViews specification given by:

$$
\ln \left(\sigma_{t}^{2}\right)=\alpha_{0}+\beta \ln \left(\sigma_{t-1}^{2}\right)+\alpha\left|\frac{\varepsilon_{t-1}}{\sigma_{t-1}}\right|+\gamma \frac{\varepsilon_{t-1}}{\sigma_{t-1}}
$$

The fact that the EGARCH process is specified in terms of $\log$ of the conditional variance implies that $\sigma_{t}^{2}$ is always positive and, consequently, there are no restrictions on the sign of the model parameters. In fact, the leverage effect is exponential, rather than quadratic, and that the forecasts can be tested by the hypothesis $\gamma<0$. 3.2.2 Model Selection Criteria

In a holistic, model comparison approach the underlying goal is to select the "best approximating model" from among competing models under consideration. Several model selection criteria have been proposed based on different considerations. The most prominently used method is the Akaike Information Criterion (AIC) (Akaike, 1978). The procedure selects the best model with the lowest AIC. Fundamentally, AIC involves the notion of cross-validation, but only on theoretical sense. Given AIC values of two or more models, the model satisfying minimum AIC is most representatives of the true model and, on this account, may be interpreted as the best approximating model among those being considered (Dayton, 2003).

Let $\mathrm{y}, \mathrm{k}, \mathrm{n}$ and LL be response variable, the number parameters, the number of observations and the maximised likelihood function respectively. The Bayesian Information Criterion is

$$
A I C=2 K-2 \ln (L L)=2 K+\ln \left(\frac{R S S}{n}\right)
$$

where, $\quad R S S=\sum_{i=1}^{n} \hat{e}^{2}$ is the residual sum of squares.

The main reason for preferring the use of a model selection procedure such as AIC in comparison to traditional significance tests is the fact that, a single holistic decision can be made concerning the model that is best supported by the data in contrast to what is usually a series of possibly conflicting significance test. Moreover, models can be ranked from best to worst supported by the data at hand, thus, enlarging the possibilities of interpretation (for more insights see Dayton, 2003).

Since, AIC serves only the purpose of model comparison; we consider three diagnostic check methods based on Ljung-Box Q statistics for post-estimation evaluation analysis of the fitted models. There are the standardised residuals and squared residuals of the Autocorrelation (AC) and partial autocorrelation (PAC) functions, and the autoregressive conditional heteroscedastic ARCH-LM test

In addition, we employ two popular out-of sample model selection criteria to evaluate the predictive performance of the five competing models considered in the investigation. The criteria are namely the Root Mean Square Error (RMSE) and the Mean Absolute Error (MAE). Thus, we have

$$
\begin{array}{r}
R M S E=\sqrt{\frac{1}{m} \sum_{t=1}^{m}\left(\hat{y}_{t}-y\right)^{2}} \\
M A E=\frac{1}{m} \sum_{t=1}^{m}\left|y_{t}-\hat{y}_{t}\right|
\end{array}
$$

where, $t=1, \ldots, m$ with $m, y_{t}$ and $\hat{y}_{t}$ denoting the number of forecasts, the actual and the forecast respectively.

The RMSE and the MAE can be jointly considered to diagnose the errors variation in a set of forecasts. The RMSE will always be larger or equal to the MAE; the greater difference between them, the greater the variance in the individual errors in the sample.

\section{Analysis of Results}

\subsection{Preliminary Results}

Table 4.1 shows the preliminary analysis statistics of various insurance stocks returns. The mean return and standard deviation are reported, as well as the highest and lowest returns observe for each stock. The standard deviation of stock returns is the measure of dispersion of returns around the average return over the period of study. 
This is not always the best indicator of risk variability. Clearly, the return series displayed in Figure 4.1 has too many extremes values to be generated by a normal curve. Sample departures from the normal distribution are summarized by the coefficients of skewness and Kurtosis. The excess kurtosis coefficients are very large and statistically significant for all the stocks. All the stocks are negatively skewed. GARCH models allow the volatility, or conditional heteroskedascity, to vary over time; therefore it can easily take care of the fourth moment or kurtosis to the data. Nerveless, clustering conditional volatility has a limited effect on the very high skewness.

\subsection{Analysis of Main Results}

The main empirical results are summarized in the following Tables 4.2, 4.3, and 4.4 respectively. Table 4.2 gives the statistics of model variance parameters estimates and Aikake performance evaluation criterion under various fitting techniques. The results indicate with a good level of confidence the suitability of various fitting methods. In fact, the ARCH coefficient(s) of the estimated models are significant except in the cases of the second order of ARCH (2) results of UNIC and WAPIC insurance stocks price returns. Similarly, the beta coefficients of all the stocks are also significant at $99 \%$ confidence level, which indeed shows the presence of time-clustering volatility of insurance stocks in Nigerian market. On the other hand, the asymmetry gamma coefficients of the EGARCH are significant in for all the nine companies whereas the TGARCH are significant in six out of the nine stocks. But even in the case of the latter three companies, the non linear asymmetric TGARCH model is very competitive as expected based on the kurtosis and skewness coefficients results given in Table 4.1. Moreover, the EGARCH $(1,1)$ is in general the preferred model for these stocks using the AIC model selection criterion results as shown in Table 4.2 .

The post-estimation evaluation using the Lung-Jung and Box-Pierce statistics are quite informative in assessing the diagnostic checks of various simulated models. Table 4.3 results show that, the Autocorrelation (AC) and Partial Autocorrelation (PAC) Q(16) statistics are significant for all the fitted models in case Crusader, Guinea and UNIC insurance stocks whereas only $\mathrm{ARCH}(1)$ is significant for Cornerstone and Prestige Insurance companies stocks. Similarly, in the case of Niger Insurance only ARCH (1) and EGARCH $(1,1)$ are not significant. On the other hand, the $\mathrm{Q}(16)$ statistics for the standardized squared residuals are significant for all the simulated models only in the case of UNIC Insurance. In fact, the situation remains persistent even when we tried higher level Lags. This can be seen also easily from the ARCH-LM test Q statistics results. In fact, the ARCH test is only significant in the case of UNIC with even higher order ARCH, GARCH, TGARCH and EGARCH. This corroborates Chahal and Wang (1998) findings that time-varying conditional volatility has a limited effect on the third moments or skewness.

Table 4.4 results show the RMSE and MAE out-of sample forecasts comparison. The results suggest that, the non-linear methods perform better than other competing methods. In fact, the Exponential GARCH $(1,1)$ model proves to be very competitive as it performs better than other competing methods using the RMSE and MAE model forecast evaluation criteria. This is closely follows by the TGARCH $(1,1)$ and as distant third the GARCH $(1,1)$ model. However, it is important to note the closeness amongst the magnitudes of all the methods in both (RMSE and MAE) model performance statistics measures, which on a nutshell confirmed the adequacy of these conditional volatility models in modelling Nigerian insurance stock prices returns.

\section{Conclusion}

We have examined the volatility behaviour of the Nigerian insurance stocks price. Several variants of heteroskedastic conditional volatility models were evaluated using model evaluation performance metrics. The post estimation evaluation revealed that most of the models studied were competitive. However, the results show that the EGARCH is a more preferred modelling framework for evaluating risk volatility of Nigerian insurance stocks. These findings are substantiated by using AIC, RMSE, and MAE evaluation information measures. The present findings are relevant to the investing community as a whole who invest their hard-earned money on corporate insurance business expecting reasonable returns. Keeping in mind that insurance stock returns are exponentially volatile, and particularly because the Nigerian financial system is currently undergoing reforms, investors are better informed on insurance stocks in their portfolio profile.

\section{References}

Amin, K. I. \& Victor K. Ng. (1997). Inferring future volatility from the information in implied volatility in Eurodollar options: A new approach. The Review of Financial Studies, Vol. 10, No. 2, pp. 333 - 367.

Arena, Marco. (2006). Does Insurance Market Activity Promote Economic Growth? World Bank Policy Research Working Paper 4098, December 2006 Available: http://www.econ.worldbank.org.

Akaike, H. (1978). A Bayesian analysis of the minimum AIC procedure. Annals of the Institute of Statistical Mathematics, 30, 9-14. 
Baillie, Richard T. and Ramon P. DeGennaro. (1990). "Stock returns and volatility" The Journal of Financial and Quantitative Analysis, Vol. 25, No. 2, pp. 203 - 214.

Bollerslev, T. (1986). Generalised Autoregressive Conditional Heteroskedasticity. Journal of Econometrics, 51, 307-327.

Chahal, Mandeep S. \& Jun Wang. (1998). Jump diffusion processes and emerging bond and stock markets: An investigation using daily data. Multinational Finance Journal, 1( 3), $169-197$.

Chan, Kalok, Chan, K. C. \& Karolyi G. A. (1991). Intraday volatility in the stock index and stock index futures markets. The Review of Financial Studies, 4(4), $657-684$.

David, Alexander. (1997). Fluctuating confidence in stock markets: Implications for returns and volatility. The Journal of Financial and Quantitative Analysis, 32(4), 427 - 462.

Dayton, C. Mitchell. (2003). Model Comparisons Using Information Measures. Journal of Modern Applied Statistical Methods, 2(2), 281-292.

Engle, R. F. (1982). Autoregressive Conditional Heteroscedasticity with estimates of the variance of the United Kingdom inflation. Econometrica, 50, 987-1007.

Engle, R. (2001). Garch 101: The use of Arch/Garch models in applied econometrics. Journal of Economic Perspectives, 15( ), $157-168$.

Eraker, Bjorn. (2004). Do Stock Prices and Volatility Jump? Reconciling Evidence from Spot and Option prices. The Journal of Finance, 59(3), 1367-1403

Floros, Christo. (2007). The use of GARCH models for the calculation of minimum capital risk requirements: International evidence. International Journal of Managerial Finance, 3(4), 360 - 371.

Galeotti, Marzio \& Fabio Schiantarelli. (1994). Stock Market Volatility and Investment: Do Only fundamentals Matter? Economica, 61(242), 147-165

Glostan, L., R. Jagannathan, \& D. Runkle. (1993). On the Relationship between the Expected Value and the Volatility of the Nominal Excess Return on Stocks. Journal of Finance, 48, 1779-1802.

Ibiwoye, Ade and I. A. Adeleke. (2008). Is Insurance Nigeria's Next Capital Market 'Honey Pot'? African Journal of Business Management, 2(9), 157-164.

Kumar Raman \& Makhija Anil .K. (1986).Volatility Of Stock Prices and Market Efficiency. Managerial and Decision Economics, 7( 2), 119-122.

Mankiw, Gregory N.; David Romer \& Mattew D. Shapiro. (1991). Stock Market Forecastability and Volatility: A Statistical Appraisal. The Review of Economic Studies, 58(3), 455-477.

Nelson, Daniel B. (1991). Conditional Heteroskedasticity in Asset Returns: A New Approach. Econometrica, 59(2), 347-370.

Ologunde, A. O.; Elumilade, D. O. \& Asaolu, T. O. (2006). Stock Market Capitalization and Interest Rate in Nigeria: A Time Series Analysis. International Research Journal of Finance and Economics, 4, 154-167.

Olowe, Rufus Ayo. (2009). The Impact of the Announcement of the 2005 Capital Requirement for Insurance Companies on the Nigerian Stock market. The Nigerian Journal of Risk and Insurance, 6(1), 43-69.

Rydberg, Tina Hviid (2000). Realistic statistical modelling of financial data. International Statistical Review, 68(3), $233-258$.

Schwert, G. William. (1989). Why does stock market volatility change overtime? The Journal of Finance, 44(5), $1115-1153$.

Taylor, S. J. (1986). Modelling Financial time Series, John Wiley \& Sons, Chichester.

Zakoian, J. M. (1994). Threshold Heteroscedastic Models. Journal of Economic Dynamic and Control. 18, 931-955. 
Table 4.1. Summary of Descriptive Statistics of Stocks Returns

\begin{tabular}{|c|c|c|c|c|c|c|c|}
\hline & \multirow{2}{*}{$\frac{\mathrm{N}}{\text { Statistic }}$} & \multirow{2}{*}{$\begin{array}{l}\text { Minimum } \\
\text { Statistic }\end{array}$} & \multirow{2}{*}{$\begin{array}{l}\text { Maximum } \\
\text { Statistic }\end{array}$} & \multirow{2}{*}{$\frac{\text { Mean }}{\text { Statistic }}$} & \multirow{2}{*}{$\begin{array}{l}\text { Std. Deviation } \\
\text { Statistic }\end{array}$} & \multicolumn{2}{|c|}{ Higher Moments } \\
\hline & & & & & & Skewness & Kurtosis \\
\hline AIICO & 1902 & -.701 & .499 & .00019 & .045752 & -2.508 & 65.311 \\
\hline Cornerstone & 1902 & -.589 & .435 & .00022 & .042087 & -3.131 & 60.339 \\
\hline Crusader & 1902 & -.599 & .451 & .00068 & .033880 & -3.235 & 85.909 \\
\hline GUINEA & 1902 & -.288 & .288 & .00058 & .018662 & -.001 & 62.017 \\
\hline Law Union & 1902 & -.361 & .267 & .00073 & .028789 & -.967 & 23.139 \\
\hline NIGER & 1902 & -.458 & .153 & -.00007 & .037106 & -1.955 & 20.297 \\
\hline Prestige & 1902 & -.440 & .307 & .00053 & .032567 & -2.362 & 35.255 \\
\hline UNIC & 1902 & -1.099 & .300 & -.00005 & .045919 & -7.124 & 174.714 \\
\hline WAPIC & 1902 & -.517 & .454 & .00100 & .038572 & -1.428 & 51.581 \\
\hline
\end{tabular}
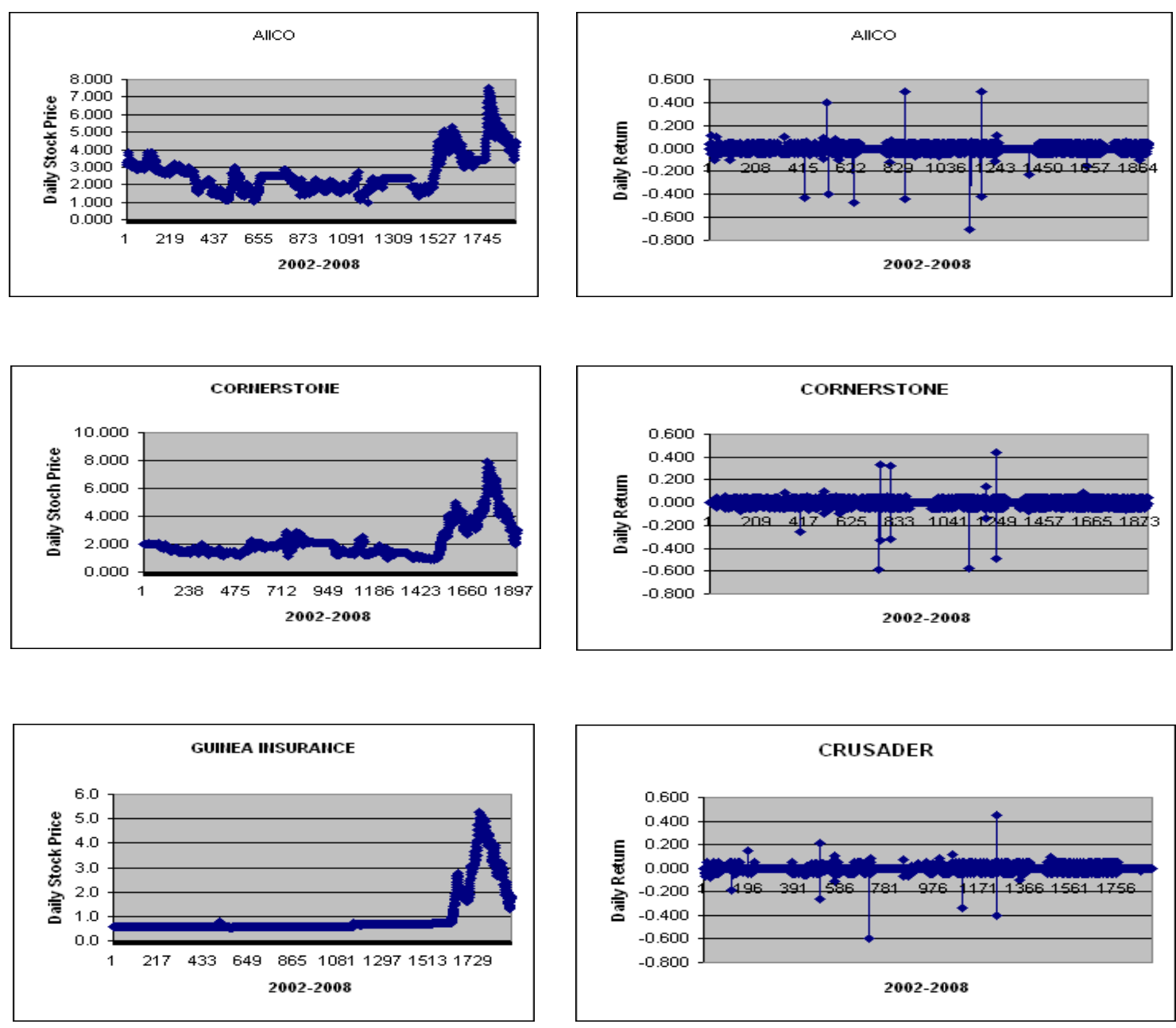

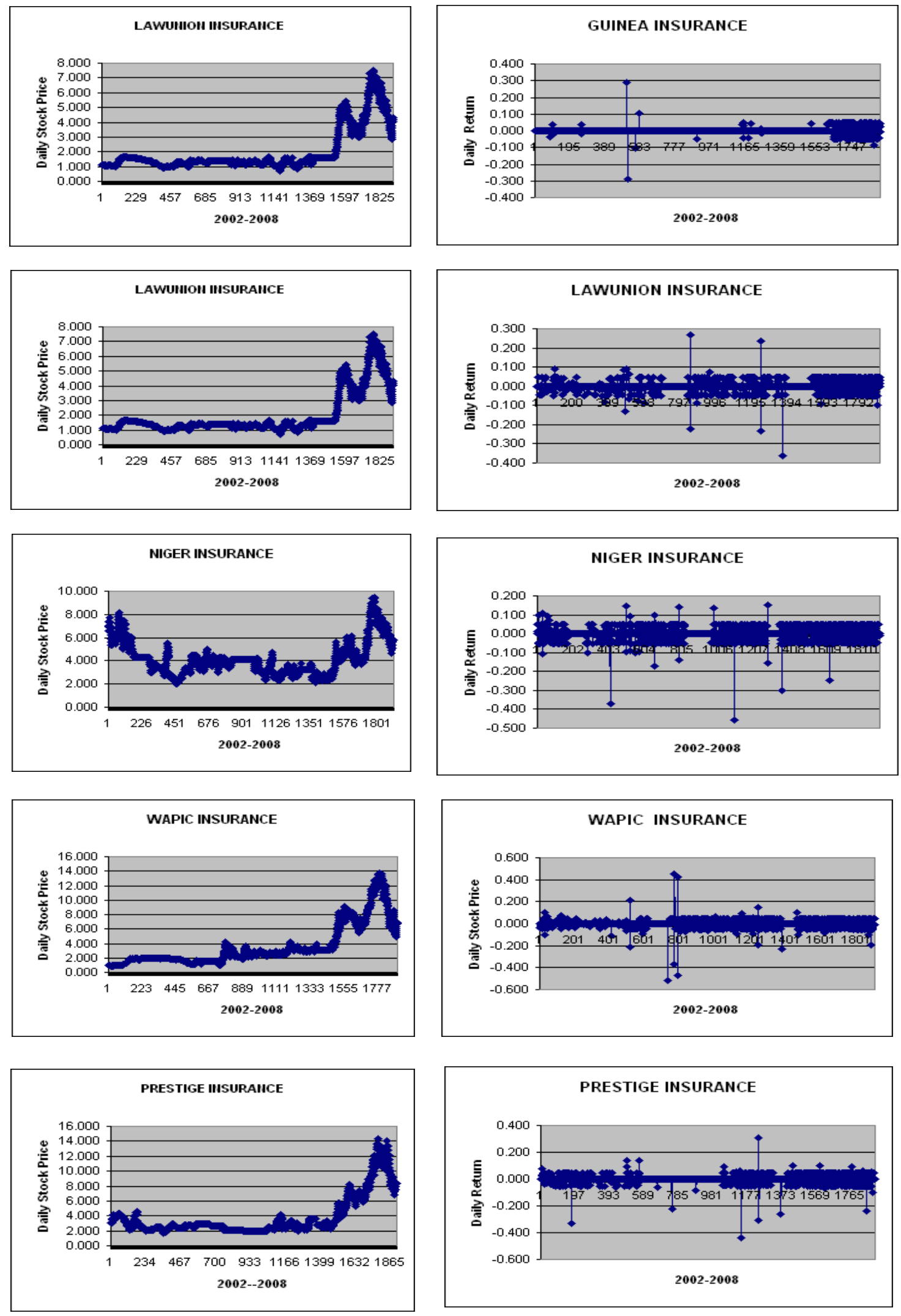

Figure 4.1. Stocks Prices and their Rates of Return Plots 
Table 4.2. Summary of Model Parameters Estimation Statistics and Goodness of Fit

\begin{tabular}{|c|c|c|c|c|c|c|}
\hline \multirow{2}{*}{$\begin{array}{l}\text { Insurance Stocks } \\
\text { Return }\end{array}$} & \multicolumn{5}{|c|}{ Coefficients } & \multirow{2}{*}{$\frac{\text { Model Fit }}{\text { AIC }}$} \\
\hline & Model & \multicolumn{2}{|r|}{$\alpha_{2}$} & $\beta$ & $\gamma$ & \\
\hline AIICO & $\mathrm{ARCH}(1)$ & $0.5993 *$ & & & & -3.5070 \\
\hline Cornerstone & $\mathrm{ARCH}(2)$ & $0.2830^{*}$ & $1.1449 *$ & & & -3.6823 \\
\hline Crusader & $\operatorname{GARCH}(1,1)$ & $0.6735^{*}$ & & $0.6043 *$ & & -3.6390 \\
\hline Guinea & TARCH $(1,1)$ & $0.8370^{*}$ & & $0.6637 *$ & $-0.6202 *$ & -3.6802 \\
\hline LawUnion & $\operatorname{EGARCH}(1,1)$ & $0.5805^{*}$ & & $0.8002 *$ & $0.2542 *$ & -3.7451 \\
\hline Niger & $\mathrm{ARCH}(1)$ & $0.6875^{*}$ & & & & -3.6151 \\
\hline Prestige & $\mathrm{ARCH}(2)$ & 0.3405 & $0.8349 *$ & & & -3.7813 \\
\hline Unic & GARCH $(1,1)$ & $0.2856^{*}$ & & $0.8128^{*}$ & & -3.9609 \\
\hline Wapic & $\operatorname{TARCH}(1,1)$ & $0.2942 *$ & & $0.8224^{*}$ & $-0.0514 *$ & -3.9601 \\
\hline & EGARCH $(1,1)$ & $0.4516^{*}$ & & $0.6558 *$ & $-0.2131 *$ & -4.0170 \\
\hline & $\mathrm{ARCH}(1)$ & $1.0829 *$ & & & & -4.3249 \\
\hline & $\mathrm{ARCH}(2)$ & $0.9798 * *$ & $0.4796^{*}$ & & & -4.4873 \\
\hline & GARCH $(1,1)$ & $0.3487 *$ & & $0.7747 *$ & & -4.7079 \\
\hline & TARCH $(1,1)$ & $0.4257^{*}$ & & $0.7784^{*}$ & $-0.1732 *$ & -4.7208 \\
\hline & EGARCH $(1,1)$ & $0.8225^{*}$ & & $0.4005 *$ & $0.2010^{*}$ & -4.7511 \\
\hline & $\mathrm{ARCH}(1)$ & $1.0821 *$ & & & & -5.6918 \\
\hline & $\mathrm{ARCH}(2)$ & $0.6135^{*}$ & $0.2904 *$ & & & -5.7227 \\
\hline & GARCH $(1,1)$ & $0.2870^{*}$ & & $0.6624 *$ & & -6.1059 \\
\hline & $\operatorname{TARCH}(1,1)$ & $0.2774 *$ & & $0.6760 *$ & -0.0274 & -6.1109 \\
\hline & EGARCH $(1,1)$ & $0.5935^{*}$ & & $0.5965^{*}$ & $0.0776^{* *}$ & -6.1121 \\
\hline & $\mathrm{ARCH}(1)$ & $0.3952 *$ & & & & -4.4568 \\
\hline & $\mathrm{ARCH}(2)$ & $0.3194 *$ & $0.2041 *$ & & & -4.4813 \\
\hline & GARCH $(1,1)$ & $0.1116^{*}$ & & $0.9155^{*}$ & & -4.6944 \\
\hline & TARCH $(1,1)$ & $0.1180 * *$ & & $0.9168 *$ & -0.0197 & -4.6626 \\
\hline & EGARCH $(1,1)$ & $0.3549^{*}$ & & $0.6853 *$ & $0.0569^{* *}$ & -4.6504 \\
\hline & $\mathrm{ARCH}(1)$ & $0.7097 *$ & & & & -3.8990 \\
\hline & $\mathrm{ARCH}(2)$ & $0.4751 *$ & $0.5148 *$ & & & -3.9928 \\
\hline & $\operatorname{GARCH}(1,1)$ & $0.2375^{*}$ & & $0.8152 *$ & & -4.1665 \\
\hline & TARCH $(1,1)$ & $0.2320^{*}$ & & $0.8149 *$ & 0.0116 & -4.1655 \\
\hline & $\operatorname{EGARCH}(1,1)$ & $0.2938^{*}$ & & $0.8699 *$ & $0.0650 * *$ & -4.1747 \\
\hline & $\mathrm{ARCH}(1)$ & $0.6546^{*}$ & & & & -4.2656 \\
\hline & $\mathrm{ARCH}(2)$ & $0.6457 *$ & $0.3578^{*}$ & & & -4.2999 \\
\hline & GARCH $(1,1)$ & $0.3897^{*}$ & & $0.6120^{*}$ & & -4.3854 \\
\hline & TARCH(1,1) & $0.4222 *$ & & $0.6176^{*}$ & $-0.0774 *$ & -4.3852 \\
\hline & $\operatorname{EGARCH}(1,1)$ & $0.5302 *$ & & $0.5115^{*}$ & $-0.0767^{*}$ & -4.3849 \\
\hline & $\mathrm{ARCH}(1)$ & $0.4861 *$ & & & & -3.7806 \\
\hline & $\mathrm{ARCH}(2)$ & $0.4854 *$ & 4.49E-05 & & & -3.7795 \\
\hline & GARCH $(1,1)$ & $0.4816^{*}$ & & $0.1729 *$ & & -3.7793 \\
\hline & $\operatorname{TARCH}(1,1)$ & $0.4373^{*}$ & & $0.1463 *$ & $0.0864 *$ & -3.7789 \\
\hline & $\operatorname{EGARCH}(1,1)$ & $0.5611^{*}$ & & $0.8177 *$ & $-0.0709 *$ & -3.8360 \\
\hline & $\mathrm{ARCH}(1)$ & $0.3545^{*}$ & & & & -3.9061 \\
\hline & $\mathrm{ARCH}(2)$ & $0.3498^{*}$ & 0.0041 & & & -3.9052 \\
\hline & GARCH $(1,1)$ & $0.3495^{*}$ & & $0.1280^{*}$ & & -3.9052 \\
\hline & TARCH $(1,1)$ & $0.4155^{*}$ & & $0.0990 *$ & $-0.1240 *$ & -3.9052 \\
\hline & EGARCH $(1,1)$ & $0.4654 *$ & & $0.6391 *$ & $0.0382 *$ & -3.9075 \\
\hline
\end{tabular}

* Significant at 1\%; $\quad * *$ is significance at 5\%; $\quad$ AIC is the Aikake Information Criterion 
Table 4.3. Post Estimation Model Evaluation of Various Fitting Methods

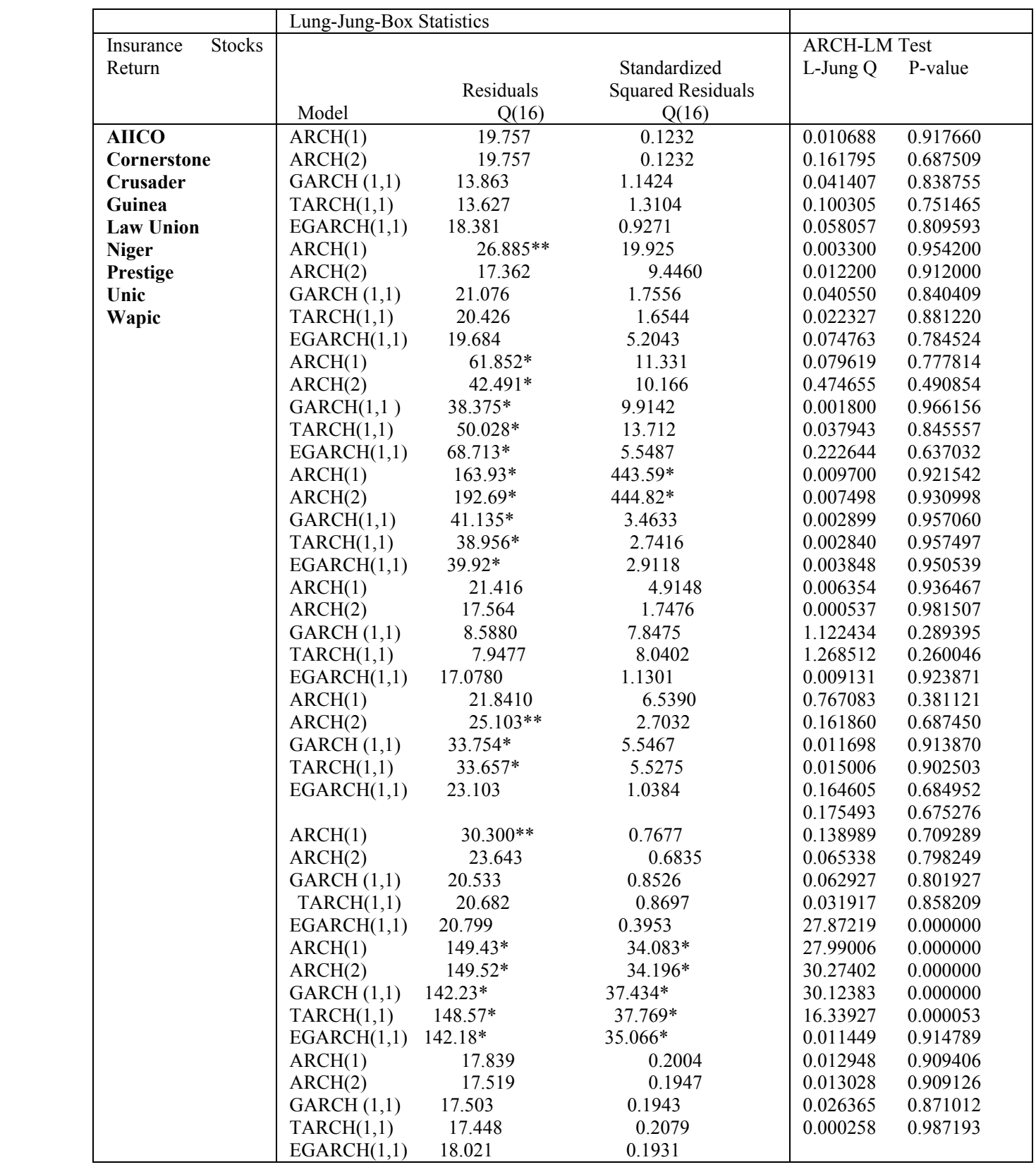

\footnotetext{
* Significant at $1 \% \quad * *$ significance at $5 \%$
} 
Table 4.4. Out-of Sample Forecast Performance of Fitted Volatility Models

\begin{tabular}{|c|c|c|c|}
\hline $\begin{array}{l}\text { Insurance Stocks } \\
\text { Return }\end{array}$ & Model & RMSE & MAE \\
\hline AIICO & $\mathrm{ARCH}(1)$ & 0.045946 & 0.026017 \\
\hline Cornerstone & $\mathrm{ARCH}(2)$ & 0.045942 & 0.025999 \\
\hline Crusader & GARCH $(1,1)$ & 0.045890 & 0.025735 \\
\hline Guinea & $\operatorname{TARCH}(1,1)$ & 0.045788 & 0.025049 \\
\hline Law-Union & $\operatorname{EGARCH}(1,1)$ & 0.045741 & 0.024257 \\
\hline Niger & $\mathrm{ARCH}(1)$ & 0.042076 & 0.023657 \\
\hline Prestige & $\mathrm{ARCH}(2)$ & 0.042103 & 0.024229 \\
\hline Unic & GARCH $(1,1)$ & 0.042081 & 0.023784 \\
\hline \multirow[t]{37}{*}{ Wapic } & TARCH $(1,1)$ & 0.042081 & 0.023781 \\
\hline & $\operatorname{EGARCH}(1,1)$ & 0.042076 & 0.023615 \\
\hline & $\mathrm{ARCH}(1)$ & 0.033918 & 0.015998 \\
\hline & $\mathrm{ARCH}(2)$ & 0.033911 & 0.015914 \\
\hline & GARCH $(1,1)$ & 0.033895 & 0.015666 \\
\hline & $\operatorname{TARCH}(1,1)$ & 0.033886 & 0.015477 \\
\hline & $\operatorname{EGARCH}(1,1)$ & 0.033878 & 0.015283 \\
\hline & $\mathrm{ARCH}(1)$ & 0.018666 & 0.006173 \\
\hline & $\mathrm{ARCH}(2)$ & 0.018664 & 0.006210 \\
\hline & GARCH $(1,1)$ & 0.018660 & 0.006337 \\
\hline & $\operatorname{TARCH}(1,1)$ & 0.018658 & 0.006439 \\
\hline & $\operatorname{EGARCH}(1,1)$ & 0.018660 & 0.006161 \\
\hline & $\mathrm{ARCH}(1)$ & 0.028822 & 0.015122 \\
\hline & $\mathrm{ARCH}(2)$ & 0.028827 & 0.015187 \\
\hline & GARCH $(1,1)$ & 0.028827 & 0.015187 \\
\hline & $\operatorname{TARCH}(1,1)$ & 0.028825 & 0.015160 \\
\hline & EGARCH $(1,1)$ & 0.028819 & 0.015074 \\
\hline & $\mathrm{ARCH}(1)$ & 0.037125 & 0.024738 \\
\hline & $\mathrm{ARCH}(2)$ & 0.037100 & 0.024316 \\
\hline & GARCH $(1,1)$ & 0.037100 & 0.024336 \\
\hline & $\operatorname{TARCH}(1,1)$ & 0.037101 & 0.024341 \\
\hline & EGARCH $(1,1)$ & 0.037097 & 0.024131 \\
\hline & $\mathrm{ARCH}(1)$ & 0.032594 & 0.017305 \\
\hline & $\mathrm{ARCH}(2)$ & 0.032617 & 0.017609 \\
\hline & GARCH $(1,1)$ & 0.032602 & 0.016867 \\
\hline & TARCH $(1,1)$ & 0.032598 & 0.016802 \\
\hline & EGARCH $(1,1)$ & 0.032580 & 0.016377 \\
\hline & $\mathrm{ARCH}(1)$ & 0.045908 & 0.028630 \\
\hline & $\mathrm{ARCH}(2)$ & 0.045908 & 0.028630 \\
\hline & GARCH $(1,1)$ & 0.045910 & 0.028703 \\
\hline & $\operatorname{TARCH}(1,1)$ & 0.045912 & 0.028735 \\
\hline & $\operatorname{EGARCH}(1,1)$ & 0.045907 & 0.028516 \\
\hline & $\mathrm{ARCH}(1)$ & 0.038597 & 0.020857 \\
\hline & $\mathrm{ARCH}(2)$ & 0.038597 & 0.020852 \\
\hline & $\operatorname{GARCH}(1,1)$ & 0.038597 & 0.020852 \\
\hline & TARCH $(1,1)$ & 0.038589 & 0.020726 \\
\hline & EGARCH $(1,1)$ & 0.038582 & 0.020711 \\
\hline
\end{tabular}

RMSE $=$ Root Mean Square Error, MAE = Mean Absolute Error 